\title{
O papel do coordenador pedagógico nas escolas públicas paulistanas: entre as questões pedagógicas e o gerencialismo
}

\section{The role of the pedagogical coordenator in the public schools in São Paulo: amongst the pedagogical questions and managerialism}

\author{
Isabel Melero Bello* \\ Marieta Gouvêa de Oliveira Penna*
}

\begin{abstract}
RESUMO
Trata-se neste artigo do papel atribuído ao coordenador pedagógico nas escolas municipais paulistanas. O objetivo é identificar tendências na função desse profissional, tendo as Diretrizes Curriculares do Curso de Pedagogia (BRASIL, 2006) e a Política Nacional de Formação de Professores (BRASIL, 2009) como principais marcos regulatórios. Para o desenvolvimento da pesquisa, foi feito levantamento de editais de concurso de ingresso e acesso para o cargo de coordenador pedagógico publicados entre 2006 e 2015, a fim de mapear as principais atribuições a ele designadas. Recorreu-se, também, à entrevista semiestruturada com coordenadoras da rede, com o intuito de compreender o que pensam e como realizam suas atribuições. Nas análises, são mobilizados os conceitos de gerencialismo e performatividade (BALL, 2002,2005 ) referidos à utilização calculada de técnicas e artefatos para organizar as relações entre os seres humanos a partir de novos valores e sistema ético, baseados na competição, eficiência, produtividade e cumprimento de metas, exigidos pela reconfiguração do capitalismo. Nas entrevistas e nos editais, foi possível evidenciar que tais valores estão presentes em suas atribuições, mas variam em intensidade e controle com as mudanças de governo
\end{abstract}

DOI: $10.1590 / 0104-4060.49149$

* Universidade Federal de São Paulo. Departamento de Educação. Guarulhos, São Paulo, Brasil. Estrada do Caminho Velho, no 333. CEP: 07252-312. E-mails: isabel_bello@yahoo.com. br; marieta.penna@yahoo.com.br 
municipal a cada quatro anos. Destacou-se, por fim, a centralidade da ação do coordenador pedagógico na articulação das relações internas e externas à escola e como indutora das políticas estabelecidas no período analisado, tanto nos editais quanto nas falas das entrevistadas.

Palavras-chave: Coordenador pedagógico. Educação básica. Ensino público. Gestão.

\begin{abstract}
This article concerns the role attributed to pedagogical coordinators in public schools in São Paulo. The goal is to identify trends in the tasks of such professionals, having the Curricular Guidelines of the Pedagogy Course (BRASIL, 2006) and National Policy of Teacher Education (BRASIL 2009) as main regulatory marks. In order to develop the research, public admission notice and access to the position of pedagogical coordenators published between 2006 and 2015 were surveyed, to map the attributions that were appointed to them. Semi-structured interviews were also used with the coordenators of the school system, aiming at understanding what they think and how they do their attributions. In the analysis, there was an arrangement of concepts of managerialism and performativity (BALL, 2002,2005 ) that refer to the use of techniques and artifacts to organize the relations between human beings centered on new values and ethical systems, based on competition, efficiency, productivity and achievement of targets, demanded by capitalism reconfiguration. In the interviews and the public notices, it was possible to highlight that those values were present in the coordinators' attributions, but they change in intensity and control according to municipal government changes every four years. Finally, the central role of the pedagogical coordenator in external and internal actions to the school and as inducer of policies established during the period analysed became evident, not only in the public notices but also in the interviews.
\end{abstract}

Keywords: Pedagogical coordinator. Basic education. Public education. Management.

\title{
Introdução
}

De acordo com Krawczyk (1999), a relevância da autonomia da escola no que se refere à gestão pedagógica, aspecto fundamental para a melhoria da qualidade do ensino, ganha destaque nos debates educacionais nos anos de 1980. 
Azanha (1995, p. 24) argumenta que só há sentido em se falar de autonomia da escola se tal autonomia favorecer sua faceta educativa, de forma que a escola seja "[...] capaz de se debruçar sobre os seus problemas, de fazer aflorar esses problemas e de se organizar para resolvê-los".

Esse debate ganha expressão na Constituição (BRASIL, 1988), sendo ratificado pela LDB 9.394/96 (BRASIL, 1996), ao postularem que a gestão escolar deve pautar-se por princípios democráticos, a partir da organização do Projeto Político Pedagógico das escolas.

Nas reformas educacionais implantadas em diferentes países nas décadas finais do século XX, ao se verem articuladas ao ideário neoliberal, verifica-se discurso que defende a gestão dos sistemas educativos, centrada na instituição escolar e sua autonomia. Tal foco na gestão escolar, nas reformas educacionais, diz respeito à percepção de sua importância na implementação das políticas, posto ser o elo de ligação das escolas aos sistemas educativos. Para Krawczyk (1999), a autonomia escolar defendida nas novas formas de gestão propostas não se refere à preocupação com a concretização de objetivos educacionais a partir de uma identidade cultural da escola, mas ao imperativo da eficácia presente nas políticas educacionais.

Souza (2003), ao ponderar sobre a ênfase presente nas políticas educacionais, de descentralização da gestão escolar, afirma que isso se relaciona à necessidade de se conferir certa autonomia à escola na gestão de recursos, a fim de se atingir indicadores de qualidade previamente estabelecidos, e não à realização de objetivos educacionais relacionados às suas especificidades educativas.

Com o objetivo de lançar luz a esse debate, tem-se por objetivo neste artigo identificar tendências nas atribuições de um gestor em especial: o coordenador pedagógico na rede municipal de São Paulo. Para tanto, foram analisados editais de concurso de ingresso e acesso para o cargo de coordenador pedagógico publicados entre 2006 e 2015. Recorreu-se, também, à entrevista semiestruturada com coordenadoras da rede, a fim de compreender o que pensam e como realizam suas atribuições na escola.

O texto está organizado em três partes. Num primeiro momento, apresentamos discussão sobre as políticas educacionais iniciadas nos anos 1990 e as premissas nelas presentes no que se refere à atuação da equipe de gestão. Em seguida, discute-se o perfil do gestor na rede municipal de São Paulo a partir do disposto em editais de concurso. Num terceiro momento, as práticas pedagógicas dos gestores são debatidas, tendo como fonte entrevistas com coordenadores pedagógicos sobre sua atuação nas escolas. 


\section{Políticas educacionais e centralidade na gestão escolar}

As políticas educacionais na atualidade estão permeadas pelo discurso da qualidade na educação, compreendida como cumprimento de metas preestabelecidas e auferidas a partir de mecanismos de avaliação externa. Vinculam-se ao enxugamento das funções do Estado em relação aos gastos e aos investimentos sociais que, no entanto, não comprometem a lógica também presente nesse ideário de fortalecimento do Estado, no que diz respeito ao seu poder decisório e de gerenciamento e controle da educação, e que na atualidade ocorre, entre outras formas, por meio de mecanismos de medição e avaliação dos resultados obtidos nas escolas por alunos e professores (GENTILI, 1999).

Os efeitos da avaliação externa sobre a organização do trabalho pedagógico e a prática docente foram investigados por Barbosa e Vieira (2013). As autoras detectaram que o atual cenário educacional, caracterizado pelo foco nos resultados de avaliações padronizadas e no cumprimento de metas, tem provocado alterações nas condições de trabalho dos professores e no cotidiano escolar, com a introdução de novas formas de gestão pedagógica.

De acordo com Oliveira (2008), a transferência de maior responsabilização às escolas altera aspectos da gestão, que passa a focar a produtividade. A descentralização administrativa e financeira, consequência de novos modelos de gestão, transfere às escolas e a seus docentes a responsabilidade pela adoção de medidas eficazes para a resolução dos problemas enfrentados no cotidiano, a partir de metas, conteúdos e estratégias previamente determinadas. Tais facetas resvalam na necessidade de introdução nas escolas de processos de gestão escolar ágeis, eficientes e modernos, de acordo com ideário neoliberal presente nas reformas educacionais (OLIVEIRA, 2015).

Ao investigar as novas formas de gestão escolar, Ball (2002) as identifica permeadas pelo que denomina de um novo gerencialismo, caracterizado pela performatividade. O gerencialismo refere-se à utilização calculada de novas técnicas e artefatos de organização das relações sociais, baseados na competição, na eficiência, na produtividade e no cumprimento de metas, ou seja, uma moral utilitarista.

A partir dessa nova cultura da gestão, a performatividade - que se refere à comparação entre desempenhos - se instaura na cultura das instituições, responsabilizando o indivíduo por sua capacidade de ser, ou não, eficiente, a partir de valores externos ao processo pedagógico. A eficácia prevalece sobre a ética, provocando individualização e destruindo solidariedades (BALL, 2005).

Ao ganhar centralidade na implementação das políticas educacionais, Barroso (2009) evidencia necessidade de se atentar para a profissionalização e 
formação dos gestores. Em relação a esse aspecto, vale destacar o que delibera a Resolução CNE/CP N ${ }^{\circ} 1 / 2006$, que Institui Diretrizes Curriculares Nacionais para o Curso de Graduação em Pedagogia, licenciatura, em seu artigo $4^{\circ}$, parágrafo único, sobre a gestão fazendo parte das atividades docentes:

As atividades docentes também compreendem participação na organização e gestão de sistemas e instituições de ensino, englobando: I - planejamento, execução, coordenação, acompanhamento e avaliação de tarefas próprias do setor da Educação; II - planejamento, execução, coordenação, acompanhamento e avaliação de projetos e experiências educativas não-escolares; III - produção e difusão do conhecimento científico-tecnológico do campo educacional, em contextos escolares e não-escolares. (BRASIL, 2006, grifo nosso).

O Parecer CNE/CP No 2/2015 que define as Diretrizes Curriculares Nacionais para a formação inicial em nível superior (cursos de licenciatura, cursos de formação pedagógica para graduados e cursos de segunda licenciatura) e para a formação continuada, com texto muito semelhante ao citado anteriormente, também ressalta a centralidade da gestão na formação de professores da educação básica, mas inclui a palavra "atuação" conforme artigo 10, parágrafo único:

As atividades do magistério também compreendem a atuação e participação na organização e gestão de sistemas de educação básica e suas instituições de ensino, englobando: I - planejamento, desenvolvimento, coordenação, acompanhamento e avaliação de projetos, do ensino, das dinâmicas pedagógicas e experiências educativas; II - produção e difusão do conhecimento científico-tecnológico das áreas específicas e do campo educacional. (BRASIL, 2015, grifo nosso).

Tendo em vista esses dois marcos regulatórios que destacam a formação e atuação dos professores da educação básica na gestão, discute-se no próximo item como essas orientações foram recontextualizadas (BALL, 1994) pelo município paulistano mediante a análise do papel do coordenador pedagógico a partir das funções a ele atribuídas em editais de concurso a fim de identificar o que se espera desse profissional dentro das escolas. Esses editais são textos, na concepção de Ball (1994), que traduzem uma política e ações dela decorrentes. 
Considera-se que, ainda que referente ao município de São Paulo, apresenta suas peculiaridades, é um modelo representativo da posição que esse profissional vem ocupando dentro das escolas brasileiras.

\section{Sobre o instituído: perfil do coordenador pedagógico na rede municipal de São Paulo}

O cargo de coordenador pedagógico para atuar nas escolas municipais paulistas foi criado pela Lei $\mathrm{N}^{\circ}$ 9.874, de 18 de janeiro de 1985. Desde então, suas funções e condições de trabalho têm sofrido alterações ao longo das gestões que se seguiram devido, em parte, à descontinuidade das políticas educacionais que caracteriza as gestões municipais paulistas (ROCHA, 2014).

Tendo em vista essa condição e o interesse deste artigo, optou-se por analisar editais de concurso para ingresso e acesso de coordenadores pedagógicos na rede municipal de ensino de São Paulo, no período 2006-2015, por considerar que aí se apresenta o perfil profissional desejado pela Secretaria Municipal de Ensino de São Paulo (SME/SP). Esses anos marcam, respectivamente, a publicação das Diretrizes Curriculares do curso de Pedagogia (BRASIL, 2006) e das Diretrizes Curriculares Nacionais para a formação inicial em nível superior (BRASIL, 2015). Tais documentos legais estabelecem, entre outros, a formação necessária para a atividade de gestor escolar da educação básica.

No município de São Paulo, a Lei No 14.660/2007 (SÃO PAULO, 2007d), publicada na primeira gestão de Gilberto Kassab, regulamentou o trabalho dos profissionais da educação da rede municipal de ensino. A lei estabelece, em seu artigo $6^{\circ}$, que há duas classes de profissionais na rede: classe de docentes e classe de gestores educacionais. Segundo o artigo $7^{\circ}$ da referida lei, compreende-se por classe, para os gestores educacionais, "o agrupamento de cargos de natureza técnica e denominação diversa". Nessa classe, inclui-se o coordenador pedagógico. Em relação às áreas de atuação, o coordenador pedagógico trabalha com a educação infantil, o ensino fundamental e o médio (artigo 11), com jornada básica de 40 horas (artigo 12). É um cargo que exige experiência anterior na docência na educação básica de três anos.

Foram localizados sete editais publicados no Diário Oficial da cidade de São Paulo entre 2007 e 2011. Em 2006 e no período 2012-2015, não foram localizados editais de concurso para esse cargo específico. No período 20072011, Gilberto Kassab estava à frente da prefeitura de São Paulo. Kassab, que foi vice-prefeito de José Serra (2005-2006), tornou-se prefeito de São Paulo pela 
primeira vez em 2006, quando Serra deixou o cargo para disputar o governo do estado de São Paulo. Em 2008, foi reeleito para novo mandato como prefeito, permanecendo até 2012. Assim, os três primeiros editais foram publicados na primeira gestão de Kassab (2006-2008), e cinco na segunda (2008-2012).

Mediante a análise dos editais, é possível perceber que na segunda gestão de Kassab houve preocupação em detalhar e expandir as atribuições do coordenador pedagógico. Sobre sua atuação na formação continuada dos professores, por exemplo, percebe-se que há na segunda gestão uma preocupação mais acentuada em avaliar impactos e estabelecer metas e estratégias de acompanhamento do que na primeira, aproximando-se do que Ball (2002) chama de "novo gerencialismo", como se vê nos exemplos abaixo:

Identificar, planejar, organizar e executar as propostas e ações voltadas ao processo de formação continuada dos docentes da Unidade Educacional. (SÃO PAULO, 2007a; 2007b; 2007c).

Elaborar o plano de trabalho da Coordenação Pedagógica indicando metas, estratégias de formação, acompanhamento e avaliação dos impactos da formação continuada e cronograma de reuniões com a Equipe Docente para Gestão Pedagógica da Unidade Educacional. (SÃO PAULO, 2009a; 2009b; 2011a; 2011b).

De acordo com os editais analisados, as atribuições do coordenador pedagógico foram aqui categorizadas em cinco eixos, tendo em vista as temáticas centrais abordadas: formação e atualização, gestão, avaliação, integração e implementação de programas e de projetos.

No eixo formação e atualização, a atuação do coordenador engloba, sobretudo, ações voltadas à ampliação dos conhecimentos dos professores da unidade escolar sobre temas educacionais e práticas consideradas relevantes pela $\mathrm{SME} / \mathrm{SP}$ e pela equipe gestora para atender necessidades identificadas mediante resultados de avaliações internas e externas. Sua função aborda o planejamento da formação continuada e a avaliação de seus impactos:

Identificar, planejar, organizar e executar as propostas e ações voltadas ao processo de formação continuada dos docentes da Unidade Educacional. (2007a; 2007b; 2007c). 
Elaborar o plano de trabalho da Coordenação Pedagógica indicando metas, estratégias de formação, acompanhamento e avaliação dos impactos da formação continuada e cronograma de reuniões com a Equipe Docente para Gestão Pedagógica da Unidade Educacional. (2009a; 2009b; 2011a; 2011b).

Também em relação a esse eixo, o coordenador pedagógico é responsável pela atualização e divulgação de novas teorias e pesquisas pedagógicas na unidade escolar, assim como das inovações tecnológicas:

Acompanhar e divulgar na Unidade Educacional as recentes teorias e pesquisas pedagógicas. (2007a; 2007b; 2007c).

Possibilitar acesso e conhecimento de diferentes recursos pedagógicos e tecnológicos disponíveis, garantindo a instrumentalização dos educadores quanto à organização e uso dos mesmos. (2007a; 2007b; 2007c; 2009a; 2009b; 2011a; 2011b).

Desenvolver estudos e pesquisas que permitam ressignificar e atualizar as práticas pedagógicas em busca de adequá-las a necessidades de aprendizagens dos alunos. (2009a; 2009b; 2011a; 2011b).

No eixo gestão, agrupam-se funções relacionadas à elaboração e à implementação do projeto pedagógico da escola, ao controle do trabalho do professor, à distribuição dos alunos por turmas e grupos e também participação na decisão de questões relacionadas aos recursos financeiros da escola e sua aplicação:

Participar da elaboração de critérios de avaliação e acompanhamento das atividades pedagógicas desenvolvidas na Unidade Educacional, bem como na organização e remanejamento de educandos em turmas e grupos. (2007a; 2007b; 2007c; 2009a; 2009b; 2011a; 2011b).

Coordenar a elaboração e implementação dos Planos de Ensino dos professores, garantindo a consonância com as diretrizes curriculares da Secretaria Municipal de Educação. (2009a; 2009b; 2011a; 2011b). 
Participar das diferentes instâncias de tomada de decisão quanto à destinação de recursos financeiros, materiais e humanos da Unidade Educacional. (2009a; 2009b; 2011a; 2011b).

Um terceiro eixo se refere à avaliação. Funções relacionadas a esse eixo ganham força na segunda gestão de Gilberto Kassab, sobretudo as externas:

Promover a análise dos resultados das avaliações internas e externas da aprendizagem dos alunos estabelecendo conexões com a elaboração do PP, Plano de Ensino e do Plano de Trabalho da Coordenação Pedagógica. (2009a; 2009b; 2011a; 2011b).

Percebe-se que as avaliações internas e externas são a principal referência para planejar as ações que visam reverter problemas detectados no desempenho dos alunos, seguindo-se uma perspectiva meritocrática do que seja o processo educativo. Ou seja, ignoram-se outros fatores que podem afetar o processo de aprendizagem dos alunos.

Outro eixo identificado se refere à integração. Segundo os editais analisados, o coordenador pedagógico é responsável pela integração entre os vários agentes que participam da escola: equipe gestora, professores, comunidade.

Participar na elaboração, articulação e implementação de ações integrando a Unidade Educacional à comunidade e às organizações sociais voltadas para as práticas educacionais. (2007a; 2007b; 2007c; 2009a; 2009b; 2011a; 2011b).

Planejar ações para a garantia do trabalho coletivo docente e para a promoção da integração dos profissionais que compõem a Equipe Técnica da Unidade Educacional. (2009a; 2009b; 2011a; 2011b).

Nesse sentido, cabe ao coordenador pedagógico sistematizar e divulgar projetos e práticas inovadoras desenvolvidas pela escola, assim como demais informações sobre o trabalho pedagógico junto à comunidade e à rede de ensino. Pressupõe-se que essa estratégia visa estimular outras escolas a desenvolverem trabalhos semelhantes, assim como também pretende divulgar as ações exitosas 
promovidas pela rede para a comunidade externa: "Promover a sistematização e divulgação dos projetos e/ou práticas inovadoras desenvolvidas pela Unidade Educacional". (2007a; 2007b; 2007c).

Por fim, relacionado ao anterior, destaca-se o eixo implementação de projetos e programas propostos pela rede de ensino. Essas ações são voltadas normalmente para questões específicas, tais como alfabetização e letramento, educação para os direitos humanos, inclusão, entre outros. A responsabilidade pela viabilização desses projetos e programas cabe ao coordenador pedagógico, como revelam algumas atribuições descritas abaixo:

Promover a implementação dos Programas e Projetos da Secretaria Municipal de Educação por meio da formação dos professores da Unidade Educacional, bem como do acompanhamento da aprendizagem dos alunos (avanços, dificuldades, necessidades específicas, etc.). (2009a; 2009b; 2011a; 2011b).

Mediante os dados apresentados, percebe-se que o coordenador pedagógico é o responsável na escola pelas funções inerentes ao fazer pedagógico, inclusive o de garantir a implementação de políticas advindas da SME/SP, acumulando um grande número de atribuições. Também funções administrativas lhe são impostas, tais como participar das decisões sobre o uso dos recursos financeiros da escola.

Contudo, os editais de concurso são textos que sofrem leituras diversas, tendo em vista os diversos leitores a que estão sujeitos e às condições de sua realização. Nesse sentido, no próximo item, os coordenadores pedagógicos falam sobre suas funções na escola e como as desenvolvem, permitindo que se olhe para o que Ball (1994) chama de contexto da prática.

\section{Realização do trabalho pedagógico: o que dizem os coordenadores sobre sua atuação}

A fim de verificar facetas sobre as maneiras como o exercício da coordenação era percebido e executado na rede pública municipal de São Paulo, quatro coordenadoras que atuam em escolas distintas foram entrevistadas. Todas possuíam formação em Pedagogia. Maria ${ }^{1}$ também era formada em História,

1 Os nomes aqui utilizados são fictícios. 
Ana em Letras e Cris estava fazendo Mestrado. No que se refere ao tempo de trabalho, Rosa possuía 20 anos na docência e 07 na gestão; Ana, 20 anos na docência e 14 na gestão; Maria, 18 anos na docência e 10 na gestão; Cris, 07 anos na docência e 04 na gestão. Ao se manifestarem sobre os motivos que as levaram a assumir a coordenação, foram mencionados aspectos como melhorar a situação financeira, ou mesmo ter uma visão mais abrangente sobre a organização do trabalho na escola e incidir sobre sua realização. Para elas, a essência do trabalho na coordenação refere-se a dar suporte pedagógico aos professores, estimulando o trabalho coletivo. A formação dos professores foi mencionada por todas como faceta central, como se vê no excerto abaixo:

O principal papel é a formação do professor [...]. Não adianta ser tarefeira... é bom para apagar incêndio, mas mudança, promover reflexão em relação ao seu próprio trabalho... isso é só na formação, e mesmo assim é trabalho de formiguinha.... (Cris, entrevista, 2016).

Também, expressaram ser importante conduzir a coordenação de modo a interferir positivamente no andamento do trabalho pedagógico nas escolas. Nas atividades cotidianas, entendiam a coordenação como um espaço de mediação entre a direção e os professores, e também entre as demandas da SME/SP e o trabalho desenvolvido nas escolas. Esse trabalho de mediação nem sempre era realizado sem tensões:

Muitas vezes fica um impasse entre professores e diretor, e o coordenador fica no meio. Fica difícil, com muita sobrecarga. (Ana, entrevista, 2016).

Placco et al. (2012, p. 761) também identificaram a existência de tensões no trabalho do coordenador pedagógico, sejam internas à escola (na relação com a direção, professores, pais e alunos), sejam externas à escola (na relação com o sistema de ensino e com a sociedade). Em meio a essa cadeia de tensões, as coordenadoras entrevistadas expressaram compreensão de seu papel como um elo importante entre a escola e a SME/SP. Essa compreensão por parte das coordenadoras se aproxima das atribuições elencadas nos editais de concurso para ingresso e acesso analisados anteriormente.

Ao discorrerem sobre a percepção que possuíam sobre seu papel frente à SME/SP, enfatizaram o coordenador como um indutor das políticas educacionais: 
Quando eu vou numa formação do DOT ${ }^{2}$ eles vão falar sobre as políticas e da aplicação dessas políticas na escola. É uma formação para inculcar nos coordenadores as políticas. (Cris, entrevista, 2016).

Sobre esse aspecto Krawczyk (1999) relata que a gestão escolar, e dentro dela a coordenação, não se refere apenas ao interior da escola, mas possui forte vinculação com a gestão do sistema educativo. No desenvolvimento de seu trabalho, as coordenadoras entrevistadas sentiam fortes cobranças por parte da SME/SP. Cabe ressaltar que Cris apontou diferenças entre as gestões municipais, ao se referir aos modos como essa cobrança era feita e sobre o que ela incidia:

A outra politica era conservadora, de controle. Essa politica não é, mas é uma política. [...]. O DOT anterior ${ }^{3}$ tinha muita cobrança. Eles iam na escola, passavam de sala em sala, olhavam os cadernos dos alunos... se você estava fazendo o que foi orientado [...]. Mas cada gestão faz de um jeito. Essa gestão é bem diferente da gestão anterior. A gestão anterior tinha um olhar muito técnico da educação. Essa gestão já tem um olhar mais sociológico. Então, eu tenho muito mais afinidade com essa gestão do que com a gestão anterior. (Cris, entrevista, 2016).

Pela fala da coordenadora, percebe-se que ela tem consciência do papel indutor de políticas municipais que assume na escola em que atua. Percebe-se também como as diferentes gestões afetam sua função, mostrando que as políticas adotadas pela SME/SP sofrem flutuações, como já apontado (ROCHA, 2014). De todo modo, foi possível verificar que o coordenador ocupa lugar estratégico na mediação com os sistemas de ensino, em decorrência do forte contato que possui com os professores. Sobre esse aspecto, Oliveira (2015) destaca a escola como núcleo da gestão das políticas educacionais, para o qual o papel do coordenador adquire centralidade. A escola precisa seguir uma série de recomendações, e as decisões vindas dos órgãos centrais costumam ser impostas e não debatidas, tal como expressou Maria:

Não há abertura para que os coordenadores sugiram alterações e construam junto aos órgãos centrais, políticas públicas, infelizmente há pouca permeabilidade. (Maria, entrevista, 2016).

2 Departamento de Orientação Técnica da SME/SP.

3 A gestão anterior, a que a coordenadora se refere, é a de Gilberto Kassab (PSD), entre 2009 e 2012. As entrevistas foram realizadas na gestão do prefeito Sérgio Haddad, do PT (2013-2016). 
Souza (2003), ao discutir a descentralização da gestão presente nas políticas educacionais de cunho neoliberal e a autonomia das escolas, pondera que as equipes de gestão atuam sobre o que já está previamente decidido pelo órgão central ao qual estão submetidas. Tal aspecto se evidenciou nas entrevistas, conforme excerto abaixo:

O trabalho pedagógico é gerido por instruções vindas da SME/SP. Toda a documentação produzida sobre nossas atividades passa pela aprovação na figura do supervisor e isso se dá com base em projetos e programas de governo municipal. (Maria, entrevista, 2016).

Como já afirmado, o coordenador é importante elo tanto entre os órgãos centrais e a escola como no interior da escola. Em seu cotidiano, se esforçava para a criação de espaços para reflexão compartilhada:

Quando de fato criamos vínculo com a equipe de professores, é possivel interferir mais, isso leva tempo, não podemos chegar impondo, tem que ter diálogo. Tem que estabelecer uma relação de proximidade e parceria, para cima e para baixo. (Rosa, entrevista, 2016).

Essa questão se refere ao papel integrador do coordenador pedagógico, atribuição presente nos editais analisados. Nas entrevistas, as coordenadoras manifestaram percepção sobre a importância do seu papel na promoção do trabalho coletivo e, consequentemente, na implementação de uma gestão escolar democrática:

O coordenador é fundamental para trabalhar em parceria com assistentes de direção e diretor, pautado pela ética e compromisso. Precisa ser profissional, instalar a reflexão e ação em prol de uma educação com significado. Sempre pensando no atendimento das necessidades e interesses das crianças, jovens e adultos estudantes. (Maria, entrevista, 2016).

Ao se referirem a uma gestão mais democrática, o diretor foi apontado como um possível entrave: 
Mas pode ficar à mercê do diretor, que pode ou não viabilizar o trabalho. É muito dificil trabalhar com gestores que não tenham concepção democrática de gestão. (Rosa, entrevista, 2016).

Souza (2012), ao debater a possibilidade da gestão democrática nas escolas, enfatiza-a, em seu aspecto político, como instância de poder. Destaca a gestão como representante do poder instituído na escola, configurando-se permeada por disputas, com as pessoas agindo no mais das vezes pautadas por seus próprios interesses. Nesse sentido, enfatiza que "[...] há um conjunto de motivações que leva as pessoas a se posicionarem das formas como o fazem que transcende os limites das explicações mais racionais ou pelo menos das explicações mais evidentes" (p. 167). As coordenadoras manifestaram a existência de disputas, especialmente no que se refere à direção escolar, mas também foi relatada a existência de oposição dos professores frente a ações da coordenação:

Tem dias que eu me arrependo de ter saído da sala de aula, eu sinto falta... os alunos são mais fáceis de lidar do que com os professores.... Os professores já têm uma visão de mundo.... Mais fechada. (Cris, entrevista, 2016).

Além das tensões e disputas presentes no cotidiano escolar, dentre as dificuldades encontradas na realização da coordenação, foi mencionado o excesso de trabalho, também evidenciado por Almeida et al. (2016). As autoras, ao analisarem a atuação do coordenador pedagógico nas redes estadual e municipal de São Paulo, apontam o excesso de atribuições que pesa sobre esse profissional, seja por parte do que está definido na legislação, seja por meio de cobranças dos órgãos do sistema educacional, ou mesmo pela comunidade escolar, e afirmam que dificilmente o coordenador poderá assumir todas as atribuições esperadas em relação à sua atuação. $\mathrm{O}$ aspecto pedagógico muitas vezes se vê submetido a questões burocráticas e emergenciais, que acabam por predominar. De fato, a análise dos editais revelou que a esse profissional são atribuídas inúmeras funções que, como explicitam as entrevistas, nem sempre podem ser atendidas a contento dadas as resistências e aos problemas que o cotidiano apresenta.

A sobrecarga de trabalho também foi identificada por Miziara et al. (2014) para quem o envolvimento do coordenador com questões burocráticas limita sua faceta política e pedagógica. Coelho (2015), em sua pesquisa, identifica sobrecarga no trabalho do coordenador, que acaba atuando mais em situações emergenciais, sobrando pouco tempo para um trabalho pedagógico mais efetivo 
junto aos professores, além de muitas vezes se sentirem inseguros em relação ao seu papel de liderança frente ao grupo de docentes.

\section{Considerações finais}

Com a realização da pesquisa, foi possível evidenciar a importância do coordenador pedagógico nas escolas, no que se refere à implementação de políticas educacionais, aspecto identificado nos editais de concurso. Nas entrevistas, foram captadas regularidades nas falas das coordenadoras que, no cotejo com outras pesquisas sobre a temática, dão a ver facetas de sua lida cotidiana nas escolas, e o papel fundamental que as têm como agentes que estabelecem relações entre as escolas e os sistemas educativos na efetivação das políticas educacionais.

Também, foi possível evidenciar que existiam diferenças entre as coordenadoras. Nesse aspecto, pode-se concordar com Placco et al. (2012), ao enfatizarem que o sentido atribuído ao papel de coordenador pelos sujeitos difere, em decorrência de suas experiências e trajetórias formativas. Pode-se também concordar com o afirmado por Fernandes (2011), que identificou formas de resistência no trabalho da coordenação pedagógica, ao significarem sua atuação. Nas entrevistas realizadas para esta pesquisa, as coordenadoras manifestaram forte preocupação com a realização, nas escolas, de uma educação em benefício do aluno, o que lhes conferia grande satisfação. As coordenadoras exerciam um papel que as fazia interagir com os diferentes agentes escolares o que, se por um lado era tarefa permeada por tensões, por outro, impulsionava a concretização de objetivos educacionais relacionados às especificidades de cada instituição.

Em relação ao instituído, ou seja, às atribuições do coordenador pedagógico apresentadas nos editais analisados, percebe-se que há clareza por parte das entrevistadas em relação ao que lhes é exigido, mas também que o atendimento a essas funções depende das condições concretas e também da subjetividade de cada indivíduo que faz a releitura daquilo que lhe é imposto de formas diferentes, como sinalizado por Ball (1994).

\section{REFERÊNCIAS}

ALMEIDA, L. R. et al. Legislado versus executado: análise das atribuições formativas do coordenador pedagógico. Estudos em Avaliação Educacional, São Paulo, v. 27, n. 
64, p. 70-94, jan./abr. 2016. Disponível em: <http://publicacoes.fcc.org.br/ojs/index.php/ eae/article/view/3647>. Acesso em: 23 maio 2016.

AZANHA. J. M. P. Melhoria do ensino e autonomia da escola. In: AZANHA. J. M. P. Educação: Temas polêmicos. São Paulo: Martins Fontes, 1995. p. 19-30.

BALL, S. J. What is policy? Texts, trajectories and toolboxes. In: BALL, S. J. Education reform: a critical and pos-structural approach. Philadelphia: Open University Press, 1994. p. 14-26.

BALL, S. J. Reformas escolas/reformar professores e os terrores da performatividade. Revista Portuguesa de Educação, Braga, v. 15, n. 2, p. 03-23, 2002.

BALL, S. J. Profissionalismo, gerencialismo e performatividade. Cadernos de Pesquisa, São Paulo, v. 35, n. 126, p. 539-564, set./dez. 2005.

BARBOSA, L. C. de M.; VIEIRA, L. F. Avaliações externas estaduais: possíveis implicações para o trabalho docente. Revista e-Curriculum, São Paulo, v. 02, n. 11, ago. 2013. Disponível em: <http://revistas.pucsp.br/index.php/curriculum>. Acesso em: 11 set. 2011.

BARROSO, J. A utilização do conhecimento em política: o caso da gestão escolar em Portugal. Educação e Sociedade, Campinas, v. 30, n. 109, p. 987-1007, set./dez. 2009. Disponível em: <http://www.cedes.unicamp.br>. Acesso em: 22 mar. 2016.

BRASIL. Constituição da República Federativa do Brasil de 1988. Disponível em: $<$ http://www.planalto.gov.br/ccivil_03/constituicao/constituicaocompilado.htm>. Acesso em: 10 mar. 2014.

BRASIL. Lei no 9.394, de 20 de dezembro de 1996. Estabelece as diretrizes e bases da educação nacional. Diário Oficial da União, Brasília, DF, 1996.

BRASIL. Ministério da Educação. Resolução CNE/CP No 01, de 15 de maio de 2006. Institui as Diretrizes Curriculares Nacionais para o Curso de Graduação em Pedagogia Licenciatura. Conselho Nacional de Educação - Conselho Pleno. Brasília, 2006. Disponível em: <http://portal.mec.gov.br/cne/arquivos/pdf/rcp01_06.pdf>. Acesso em: 21 de ago. 2015.

BRASIL. Ministério da Educação. Parecer CNE/CP No 2/2015, de 9 de junho de 2015. Diretrizes Curriculares Nacionais para a Formação Inicial e Continuada dos Profissionais do Magistério da Educação Básica. Conselho Nacional de Educação - Conselho Pleno, Brasília, 2015.

BRASIL. Decreto No 6.755, de 29 de janeiro de 2009. Institui a Política Nacional de Formação de Profissionais do Magistério da educação Básica, disciplina a atuação da Coordenação de Aperfeiçoamento de Pessoal de Nível Superior - CAPES no fomento a programas de formação inicial e continuada, e dá outras providências. Disponível em: $<$ https://www.capes.gov.br/images/stories/download/legislacao/Decreto-6755-2009. pdf $>$. Acesso em: 20 maio 2015. 
COELHO, F. M. O Cotidiano da Gestão Escolar: o método de caso na sistematização de problemas. Educação \& Realidade, Porto Alegre, v. 40, n. 4, p. 1261-1276, out./dez. 2015.

FERNANDES, M. J. da S. A coordenação pedagógica nas escolas estaduais paulistas: resoluções recentes e atuação cotidiana na gestão e organização escolar. Revista Brasileira de Política e Administração da Educação, Goiânia, v. 27, n. 3, p. 361-588, set./dez. 2011.

GENTILI, P. As políticas educacionais no contexto do neoliberalismo: os significados da privatização no campo educacional. In: OLIVEIRA, M. N. de (org.). As políticas educacionais no contexto da globalização. Ilhéus, BA: Editus, 1999. p. 105-130.

KRAWCZYK, N. A gestão escolar: Um campo minado... Análise das propostas de 11 municípios brasileiros. Educação e Sociedade, Campinas, ano XX, n. 67, p. 112-149, ago. 1999.

MIZIARA, L. A. S. et al. O que revelam as pesquisas sobre a atuação do coordenador pedagógico. Revista Brasileira de Estudos Pedagógicos, Brasília, v. 95, n. 241, p. 609635, set./dez. 2014.

OLIVEIRA, D. A. Las reformas educativas y sus repercusiones em el trabajo docente. In: OLIVEIRA, D. A. (Org.). Políticas educativas y trabajo docente em América Latina. Lima/Peru: Fondo Editoria UCH, 2008, p. 1752.

OLIVEIRA, D. A. Educação e planejamento: a escola como núcleo da gestão. In: DALILA, O. A. (Org.). Gestão democrática da educação: desafios contemporâneos. 11 ed. Petrópolis/RJ: Vozes, 2015. p. 64-104.

PLACCO, V. M. N. de S. et al. O coordenador pedagógico: aportes à proposição de políticas públicas. Cadernos de Pesquisa, São Paulo, v. 42, n. 147, p. 754-771, set./dez. 2012. Disponível em: http://www.scielo.br/pdf/cp/v42n147/06.pdf. Acesso em: 23 maio 2016.

ROCHA, S. da S. Atuação dos coordenadores pedagógicos da rede municipal de ensino de São Paulo: implicações políticas e sofrimento no trabalho. 2014. Dissertação (Mestrado em Educação) - Universidade Estadual de Campinas, Faculdade de Educação, Campinas, 2014.

SÃO PAULO. Prefeitura de São Paulo. Edital de abertura de inscrições e instruções especiais. Concurso de acesso para o provimento efetivo de cargos vagos de coordenador pedagógico. Diário Oficial da Cidade de São Paulo, São Paulo, SP, 15 abr. 2011a.

SÃO PAULO. Prefeitura de São Paulo. Edital de abertura de inscrições e instruções especiais. Concurso de Acesso para provimento, em caráter efetivo, de cargos vagos da Classe dos Gestores Educacionais - Coordenador Pedagógico. Diário Oficial da Cidade de São Paulo, São Paulo, SP, 22 mar. 2011b.

SÃO PAULO. Prefeitura de São Paulo. Edital de abertura de inscrições e instruções especiais. Concursos de Acesso para provimento, em caráter efetivo, de cargos vagos da Classe dos Gestores Educacionais - Coordenador Pedagógico, Diretor de Escola e Supervisor Escolar. Diário Oficial da Cidade de São Paulo, São Paulo, SP, 24 jun. 2009a. 
SÃO PAULO. Prefeitura de São Paulo. Edital de abertura de inscrições e instruções especiais. Concursos de Acesso para provimento, em caráter efetivo, de cargos vagos da Classe dos Gestores Educacionais - Coordenador Pedagógico - QPE-15, Diretor de Escola - QPE-17 e Supervisor Escolar - QPE-18 da Carreira do Magistério Municipal. Diário Oficial da Cidade de São Paulo, São Paulo, SP, 18 ago. 2009 b.

SÃO PAULO. Prefeitura de São Paulo. Edital de abertura de inscrições e instruções especiais. Concurso público de ingresso para provimento de cargos vagos da classe II professor titular de educação infantil, professor titular de ensino fundamental I, professor titular de ensino fundamental II, professor titular de ensino médio e da classe III coordenador pedagógico da carreira do magistério municipal. Diário Oficial da Cidade de São Paulo, São Paulo, SP, 5 de jun. 2007a.

SÃO PAULO. Prefeitura de São Paulo. Edital de abertura de inscrições e instruções especiais. Concurso de acesso para provimento efetivo de cargos da classe II - professor titular de educação infantil, professor titular de ensino fundamental I, professor titular de ensino fundamental II, professor titular de ensino médio e da classe III coordenador pedagógico da carreira do magistério municipal. Diário Oficial da Cidade de São Paulo, São Paulo, SP, 5 de jun. 2007b.

SÃO PAULO. Prefeitura de São Paulo. Edital de abertura de inscrições e instruções especiais. Concurso de acesso para provimento efetivo de cargos da classe II - professor titular de educação infantil, professor titular de ensino fundamental I, professor titular de ensino fundamental II, professor titular de ensino médio e da classe III coordenador pedagógico da carreira do magistério municipal. Diário Oficial da Cidade de São Paulo, São Paulo, SP, 3 jul. 2007c.

SÃO PAULO. Prefeitura de São Paulo. Lei No 14.660, de 26 de dezembro de 2007. Dispõe sobre alterações das Leis $\mathrm{N}^{\mathrm{0}} 11.229 / 1992$, No $11.434 / 1993$ e legislação subsequente, reorganiza o Quadro dos Profissionais de Educação, com as respectivas carreiras, criado pela Lei No 11.434/1993, e consolida o Estatuto dos Profissionais da Educação Municipal. Diário Oficial da Cidade de São Paulo, São Paulo, SP, 27 dez. 2007d.

SOUZA, A. R. Reformas educacionais: descentralização, gestão e autonomia escolar. Educar, Curitiba, n. 22, p. 17-49, 2003.

SOUZA, A. R. A natureza política da gestão escolar e as disputas pelo poder na escola. Revista Brasileira de Educação, Rio de Janeiro, v. 17, n. 49, p. 159-241, jan./abr. 2012.

Texto recebido em 03 de novembro de 2016. Texto aprovado em 13 de abril de 2017. 